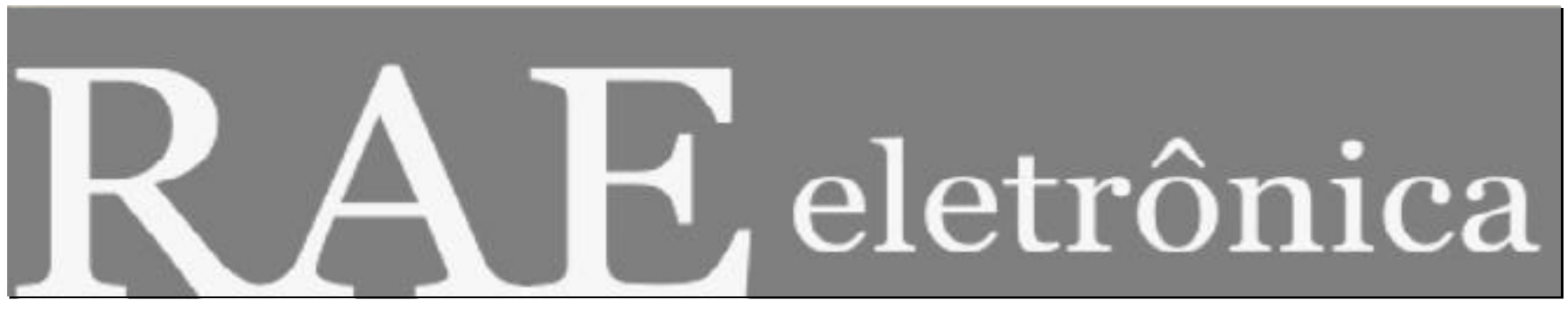

FÓRUM - NOVOS MODELOS ORGANIZACIONAIS: PARADOXOS E CONTRADIÇÕES ENTRE O DISCURSO E A PRÁTICA

\title{
DIALÉTICA DA EXCLUSÃO / INCLUSÃO EM UMA ORGANIZAÇÃO INDUSTRIAL
}

Por:

Maria Chalfin Coutinho, UFSC.

RAE-eletrônica, v. 5, n. 1, Art. 7, jan./jun. 2006

http://www.rae.com.br/eletronica/index.cfm?FuseAction=Artigo \&ID=3356\&Secao=Fórum \&Volume= $5 \&$ Numero $=1 \&$ Ano $=2006$

CCopyright, 2006, RAE-eletrônica. Todos os direitos, inclusive de tradução, são reservados. É permitido citar parte de artigos sem autorização prévia desde que seja identificada a fonte. A reprodução total de artigos é proibida. Os artigos só devem ser usados para uso pessoal e nãocomercial. Em caso de dúvidas, consulte a redação: raeredacao@fgvsp.br.

A RAE-eletrônica é a revista on-line da FGV-EAESP, totalmente aberta e criada com o objetivo de agilizar a veiculação de trabalhos inéditos. Lançada em janeiro de 2002, com perfil acadêmico, é dedicada a professores, pesquisadores e estudantes. Para mais informações consulte o site www.rae.com.br/eletronica.

RAE-eletrônica ISSN 1676-5648

(C2006 Fundação Getulio Vargas - Escola de Administração de Empresas de São Paulo.

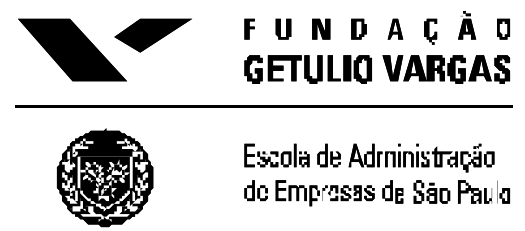




\title{
RESUMO
}

Este artigo tem como objetivo analisar os processos coletivos de identificação de trabalhadores inseridos em um grupo empresarial com estratégias participativas de gestão. Trata-se de um estudo qualitativo de metodologia empírica. Os resultados obtidos demonstram a existência de dois perfis profissionais: antigos e novos. Os antigos correspondem àqueles que ainda permaneceram, apesar de desvalorizados pela administração. Eles não têm perspectivas de progresso profissional e correm risco eminente de exclusão. Os novos correspondem aos jovens trabalhadores, mais valorizados pelos gestores, com maior escolaridade, iniciativa, habilidade para executar tarefas variadas e expectativas de progresso profissional. Esses resultados revelam a presença da dialética da exclusão/inclusão no interior da organização industrial investigada.

\section{PALAVRAS-CHAVE}

Identificação, trabalho, dialética, exclusão, inclusão.

\begin{abstract}
This article analyzes the collective identification processes of workers inserted in an industrial organization adopting participative strategies of management. The research is a qualitative study using an empirical methodology. Results demonstrate the existence of two different workers' profiles: one old and another new. Workers with an old profile perform their tasks in an old fashioned way and do not have professional growth perspectives. They are devalued by their superiors and face an imminent risk of exclusion. Those with new profile are younger workers, more valued by their managers. They have a better education, initiative, ability to execute a variety of tasks and expectations of professional progress. These results reveal the presence of an exclusion/inclusion dialectic within the industrial organization.
\end{abstract}

\section{KEYWORDS}

Identification, work, dialectic, exclusion, inclusion. 


\section{INTRODUÇÃO}

As organizações de trabalho têm passado por transformações profundas nas últimas décadas, paralelamente às mudanças políticas e econômicas no âmbito mundial. A globalização da economia e o acirramento da disputa de mercados são alguns dos fatores que ajudam a explicar a crescente competitividade das empresas capitalistas que recorrem a diferentes estratégias de modernização.

A busca de competitividade acontece no bojo de uma intensa reestruturação produtiva, com as empresas procurando substituir os clássicos padrões produtivos, associados principalmente ao taylorismo/fordismo, por novos padrões de acumulação flexível, que possibilitem a recuperação de níveis anteriores de expansão do capital (Antunes, 2000). A partir de uma investigação desenvolvida em uma organização industrial com estratégias participativas de gestão, pretendemos discutir aqui as implicações das mudanças organizacionais nos processos de identificação de seus trabalhadores.

Durante os anos 1980 do século XX a modernização das empresas brasileiras tinha seu foco principal no investimento em novos equipamentos automatizados. A partir dos anos 1990 foram ampliadas as estratégias de modernização, com a introdução de novos modelos organizacionais que associam mudanças na gestão da força de trabalho com a reorganização dos processos produtivos. Ainda que seja possível observar a introdução de diferentes modelos organizacionais, é perceptível a preponderância de formas de gestão inspiradas no modelo japonês.

Alguns autores, como Coriat (1994), compreendem o modelo japonês - toyotismo - de uma maneira bem ampla, concebendo-o não apenas como um novo paradigma de produção, mas como um novo modo de regulação, que se instalaria, dentro dos limites do capitalismo, em substituição ao modelo anterior - taylorista/fordista -, ora em crise. Contudo, a visão mais difundida no Brasil, adotada neste trabalho, associa o toyotismo com um conjunto de técnicas de gestão e organização do processo de trabalho inspirado no sistema produtivo japonês, que foram desenvolvidas, primariamente, por Ohno na fábrica Toyota. A introdução desse modelo nos países ocidentais faz parte de um conjunto de transformações na busca de alternativas para a crise.

Salerno (1993) considera que o modelo japonês incorpora, parcialmente ou de forma integrada, as seguintes técnicas ou sistemas: just-in-time, kanban, manufatura celular, círculos de controle de qualidade (CCQ), polivalência, controle de qualidade total (TQC). Ruas et al. (1993) consideram o just-in-time como um sistema de gestão mais amplo, que envolveria a aplicação de técnicas (kanban, 
TQC, CCQ) e princípios que dizem respeito à participação e ao envolvimento dos trabalhadores, criando, assim, condições fundamentais para a introdução dessas mudanças.

Na década de 1980 foi possível assistir à incorporação parcial de algumas técnicas japonesas, tendo o Brasil se destacado pela ampla difusão dos CCQs, que, aplicados de forma isolada, não alteravam as formas clássicas de organização do processo produtivo (taylorismo-fordismo). A partir das avaliações negativas dessas experiências, passa a ser desenvolvida uma metodologia gerencial mais ampla, também de inspiração japonesa, centrada na qualidade: os programas de qualidade total (PQT). A implantação dos PQT viabilizaria o aparecimento de empresas integradas e flexíveis.

\begin{abstract}
A empresa flexível é entendida como o modelo mais adequado às condições de instabilidade do mercado e de forte concorrência. Este tipo de empresa, de acordo com estratégias diferenciadas, permite combinar diferentes regimes de emprego dentro de si própria, com vista à obtenção tanto de flexibilidade funcional como flexibilidade quantitativa. A racionalização flexível constitui uma estratégia desenvolvida pelas empresas para sobreviver ou vencer na batalha pela competitividade. (KOVÁCS, 2003, p. 33).
\end{abstract}

Seja por meio da incorporação de algumas ferramentas, como o CCQ, ou de programas mais amplos, como o PQT, as estratégias gerenciais inspiradas no modelo japonês pretendem estabelecer novos compromissos com os trabalhadores nos quais o rígido controle do processo de trabalho seria substituído por estratégias mais sutis de motivação, entre as quais se destaca o incentivo à participação. Ao buscar o comprometimento, as organizações participativas incentivam o vínculo entre seus integrantes e diferentes aspectos do contexto organizacional. Em seus estudos sobre comprometimento organizacional, Bastos (1996) identifica cinco abordagens sobre o tema, mas destaca a abordagem afetiva/atitudinal, ${ }^{1}$ na qual o comprometimento é visto como uma forma de identificação do indivíduo com a organização.

Quando a empresa solicita aos seus integrantes que se engajem no seu projeto, ela também demanda por identificação com seus objetivos. Es sa demanda supõe um tipo de trabalhador diferente do que se submetia às estratégias tradicionais de gestão. Cada vez mais vem sendo enfatizada a necessidade de um novo perfil de trabalhador: qualificado, autônomo, criativo e polivalente. A gestão participativa buscaria, entre outros objetivos, a conformação desse novo perfil de trabalhador, capaz de responder "[...] às demandas exigidas pela mundialização e sua expressão mais bem acabada no interior das empresas: informatização da produção" (Wolff, 2003, p. 417).

A investigação dos perfis de trabalhadores participativos requer que se avaliem os processos de identificação coletivos desenvolvidos por eles. Na busca de maior comprometimento de seus (C) RAE- eletrônica - v. 5, n. 1, Art.7, jan./jun. 2006 
integrantes, a organização os pressiona a se identificarem com ela, com os seus valores e objetivos. Uma efetiva identificação suporia o estabelecimento de perfis profissionais relativamente homogêneos, desenvolvidos em sintonia com os valores organizacionais.

A partir das reflexões acima, foi desenvolvida uma investigação sobre as possibilidades de participação e os perfis profissionais de trabalhadores inseridos em três unidades de um grupo industrial catarinense que desenvolve estratégias de gestão que privilegiam a participação dos seus recursos humanos (Coutinho, 2000). Foi possível observar o quanto o exercício participativo desenvolvido nessa organização (chamada de grupo Alfa - nome fictício) é limitado, constituindo-se em formas parciais de participação, ou mesmo em práticas que, mesmo estimulando o sentimento de participação, não ampliam o grau de influência desses trabalhadores, constituindo em pseudoparticipação (Pateman, 1992).

As pressões das organizações participativas por identificação têm repercussões diferenciadas, dependendo do lugar que o trabalhador ocupe nas relações de trabalho. É importante considerar que o trabalhador não apenas se submete às pressões organizacionais, mas, também, pode resistir a elas, dependendo de sua identidade (pessoal e coletiva), previamente constituída (Sainsaulieu, 1988).

A gestão participativa se inspira no modelo japonês, que, originalmente, apresentava diversos problemas. Apesar disso, o envolvimento dos trabalhadores era feito por meio de uma série de contrapartidas, que incluíam a garantia de emprego para um núcleo de trabalhadores, consistindo no que Coriat (1994) chama de engajamento negociado. A realidade do mercado de trabalho, no Brasil, é bastante diferente. O desemprego está na ordem do dia. Dessa forma, pode-se pensar que, se por um lado, a falta de garantias pode dificultar a construção de um coletivo que favoreça a identificação entre os pares, por outro, também dificulta a identificação dos trabalhadores com os objetivos da empresa.

Diferentes autores vêm estudando, de uma perspectiva crítica, como as formas modernas de gestão empresarial repercutem sobre o modo de ser dos trabalhadores (Pagès et al, 1987; Labounoux, 1987; Lima, 1996 e Enriquez, 1997). Esses estudos tendem a enfatizar as implicações negativas das pressões organizacionais sobre seus integrantes, abrindo pouco espaço para suas estratégias de resistência e busca de autonomia. No entanto, referem-se, geralmente, às empresas multinacionais com estratégias gerenciais já consolidadas, inseridas em mercados estáveis. Es sa é uma realidade bem diferente da que vive grande parte das empresas no Brasil.

As organizações brasileiras vêm passando por momentos de transição, tornando difícil a apresentação de modelos consolidados de gestão com os quais seus integrantes possam se identificar completamente. Esse tipo de transição foi observado no grupo Alfa, que apresentava velhas e novas 
práticas de gestão do processo produtivo e de seus recursos humanos, constituindo uma trajetória rumo à modernização. O convívio entre o velho e o novo foi observado também nos perfis dos trabalhadores da empresa.

Este artigo analisa como trabalhadores inseridos em um grupo empresarial com estratégias participativas, mas que não apresenta, ainda, um modelo consolidado de gestão, constroem seus processos coletivos de identificação no trabalho. Para fundamentar essa análise apresenta-se uma breve revisão da literatura sobre o tema. Em seguida descreve-se a metodologia utilizada no estudo empírico. Na seqüência são descritas as principais características do processo de modernização do grupo Alfa e é apresentada a análise dos processos de identificação coletiva dos trabalhadores, que revela a coexistência de dois perfis profissionais: antigos e novos. Em seguida tecem-se algumas reflexões a respeito da dialética da exclusão/inclusão (Sawaia, 1999), apontando-se o surgimento de uma nova exclusão social (Pochmann e Amorim, 2003), já presente no interior da organização industrial estudada. Ao final apresentam-se breves considerações sobre o tema.

\section{IDENTIFICAÇÃO NAS ORGANIZAÇÕES}

A introdução de modelos organizacionais flexíveis implica, entre outras mudanças, a mobilização subjetiva dos trabalhadores envolvidos. Dessa forma, é possível afirmar, tal como faz Clôt (1990), que as mudanças tecnológicas, econômicas e organizacionais não são um simples contexto, mas sm constitutivas da atividade psicológica do sujeito. Segundo o autor, a substituição do modelo clássico de organização do trabalho, do tipo taylorista, por novas formas de gestão em fluxo contínuo, particularmente o jus-in-time, implica a passagem " [...] de uma prescrição taylorista das operações para uma prescrição just-in-time da subjetividade" (Clôt, 1990, p. 317).

Cabe lembrar, tal como foi escrito antes, que os trabalhadores não apenas se submetem às pressões organizacionais, respondendo a elas de acordo com sua identidade previamente constituída. O processo de constituição da identidade ocorre de forma dialética na relação entre indivíduo e sociedade, na qual um se identifica e se transforma a partir do outro. Nesse sentido, pode-se definir identidade social como: 
[...] à consciência de pertencer a determinado grupo social e à carga afetiva que essa pertença implica. Enquanto apresentada como um processo dialético, a identidade social facilita a incorporação de valores e normas do grupo social, implica uma participação ativa do sujeito na construção da identidade grupal e afeta o contexto histórico em que ocorrem estas relações concretas. Por sua vez, as estruturas sociológicas influenciam as representações que os indivíduos fazem de si, enquanto representações do eu. Alguns espaços de trabalho e/ou categorias profissionais, pelas suas especificidades, em geral associadas a prestígio e desprestígio social, proporcionam atributos de qualificação e/ou desqualificação ao eu (Jacques, 1996, p. 44).

Ao filtrar, selecionar, incorporar ou não suas experiências cotidianas, o sujeito procura organizar um conjunto estável, que ele percebe como sendo o seu eu. Ainda que o sujeito possa perceber sua identidade como possuindo um núcleo ou essência, estudos contemporâneos no campo da Psicologia Social têm questionado concepções teóricas essencialistas:

Apreender o sujeito de forma não essencializada, histórica e culturalmente constituído, implica operar dentro de uma perspectiva em que o sujeito nunca é idêntico a si mesmo por todo o sempre, já que guarda uma abertura para o tempo, um tempo histórico que o vai posicionar na diferença e não no mesmo, através dos tempos. O que se repetiria seria a produção, a potência de diferenciação e não o sujeito. (Guareschi et al., 2003, p. 47).

Trata-se de um processo contínuo de transformação, de mudança, de movimento ou, como coloca Ciampa (1998), a identidade humana é metamorfose, ou seja, é um "[...] processo de permanente transformação do sujeito humano, que se dá dentro de condições materiais e históricas dadas [...]" (Ciampa, 1998, p. 88). O sujeito se constitui, constrói sua identidade ao longo de sua história, em suas relações com o mundo, com os outros. Um dos campos no qual essas relações se estabelecem é o mundo do trabalho, em particular nas organizações produtivas. Se considerarmos as organizações flexíveis como um espaço de mobilização subjetiva, cabe questionar em que medida a identidade dos trabalhadores inseridos nelas é submetida ou não às pressões organizacionais.

Ao se analisarem as pressões que o ambiente de trabalho nas organizações exerce sobre a identidade dos trabalhadores, podem-se sintetizar as diferentes posições teóricas em três concepções básicas (Coutinho, 1999). Para alguns autores, os sujeitos se inserem nas organizações de trabalho com a identidade já constituída. Outros consideram as organizações modernas como espaços de dominação dos sujeitos e de identificação destes com os seus objetivos. Existem, ainda, autores que analisam as 
transformações por que passa a identidade dos trabalhadores, pressionados pelas estratégias organizacionais, mas admitem a possibilidade de espaços de resistência.

Labounoux (1987) defende a idéia de que os sujeitos se inserem nas organizações de trabalho com a identidade previamente constituída. Portanto, as tentativas das empresas de unificação das representações ou de definição de uma cultura têm um impacto limitado sobre a maioria dos seus membros. $\mathrm{O}$ autor aponta a possibilidade de resistência dos atores às imposições oficiais por meio de diferentes estratégias, como o distanciamento, uma espécie de dissidência interior; ou o desdobramento, que implicaria uma teatralização da vida organizacional e um distanciamento do real. Mesmo quando impotentes diante das pressões, os atores não seriam levados a se identificar com a organização, mas poderiam questionar sua própria identidade, em decorrência da perda de referências e da pressão para a adoção de uma identidade plasmada. Também poderiam surgir estratégias coletivas, de cumplicidade entre atores.

Tal como Labounoux (1987), Lima (1996) considera que os indivíduos intervêm na organização com uma identidade já constituída ou em processo de consolidação. Contudo, em sua investigação em uma organização com estrutura estratégica, ${ }^{2}$ observou que vêm sendo priorizadas as admissões de jovens que ainda estão construindo sua identidade e são mais vulneráveis às políticas de gestão implementadas por essas empresas. Apesar de considerar que a organização não cria nem modela a identidade de seus integrantes, Lima (1996) entende que aquela pode se utilizar de suas fragilidades, criando situações que permitam a identificação, ainda que ilusória, dos trabalhadores.

Enriquez considera que "[...] jamais o indivíduo esteve tão encerrado nas malhas das organizações [...] e tão pouco livre em relação ao seu corpo, ao seu modo de pensar, à sua psique" (Enriquez, 1997, p. 19). Isso acontece em empresas estratégicas, nas quais o planejamento é substituído por estratégias de curto prazo e todos, não apenas a elite, são capazes de buscar soluções, são jogadores que acreditam na igualdade de chances. Nesse tipo de empresa ocorre o "[...] casamento impossível entre a água e o fogo [...]” (Enriquez, 1997, p. 29), por meio de uma mistura paradoxal entre o modelo japonês, que considera o indivíduo como parte do grupo e valoriza o esforço coletivo, e o modelo americano, que privilegia o individualismo e o sucesso pessoal.

A estrutura estratégica propicia o aparecimento de sujeitos estratégicos, guerreiros, ou o que Enriquez (1997) chama de matador cool, pois não hesita diante de seus objetivos, atingindo seus fins de forma ascética. Esse tipo de empresa reforça o controle psíquico e o torna cada vez mais sutil. Todos passam a se identificar com a empresa e com os chefes de forma idealizada, criando, dessa forma, uma servidão voluntária; também aqui é importante o controle do corpo (em especial dos dirigentes). 
O papel das organizações como espaço de dominação de seus integrantes também foi estudado por Pagès et al. (1987), que desenvolveram o conceito de organização hipermoderna. Esse tipo de organização "caracteriza-se pelo desenvolvimento fantástico de seus processos de mediação, sua extensão a novas zonas (instâncias), sua interconexão cada vez mais ramificada e sua constituição em sistemas cada vez mais coerentes" (Pagès et al., 1987, p. 35). Dessa forma, os trabalhadores tornam-se impotentes para fazer frente às pressões da organização, que transforma e explora, em seu proveito, as contradições individuais, assumidas coletivamente por eles.

$\mathrm{Na}$ empresa hipermoderna o processo de identificação dos trabalhadores se despersonaliza, abandonando a figura da chefia e passando a se estabelecer diretamente com a organização. Se por um lado o trabalhador se liberta da autoridade do chefe, com o qual era obrigado a se identificar, por outro cai sob a tutela "de uma entidade impessoal que penetra na sua vida e na sua alma, de ponta a ponta" (Pagès et al, 1987, p. 37). Observa-se, assim, a despersonalização e a crescente abstração das relações de poder; com isso, os mecanismos de dominação, que visam a isolar os indivíduos e impedir a expressão coletiva das reivindicações, são reforçados.

Enriquez (1997) e Pagès et al. (1987) questionam a constituição das organizações como espaço de dominação de subjetividades, tendo em vista os processos inconscientes de identificação ali estabelecidos, favorecendo o controle sobre os integrantes. Sob a aparência de estímulo à autonomia, à participação e a criatividade, as organizações (estratégicas ou hipermodernas) são de fato espaços de aprisionamento e servidão voluntária.

Sainsaulieu (1988) também observa a vulnerabilidade da identidade individual frente às pressões do ambiente social, em que a perda da identidade seria a conseqüência da incapacidade do sujeito de se defender dessas pressões. O autor destaca o papel fundamental exercido pelo conflito na evolução do sujeito, sendo a conquista da identidade o resultado de uma vitória nas relações sociais cotidianas.

As possibilidades de acesso e defesa da identidade do sujeito, impondo-se como diferente do outro, dependem, entre outros fatores, das situações de trabalho em que ele está inserido. O acesso ao poder, nas organizações, está relacionado com o lugar ocupado e com as relações sociais estabelecidas pelos integrantes dessas organizações. $\mathrm{O}$ autor entende que as diferentes formas de pressão das organizações sobre os seus integrantes determinam vias particulares de acesso à identidade.

A vitória, como a acima citada, significa que o sujeito foi capaz de impor sua diferença na relação com o outro, enquanto a identificação (com um outro mais poderoso) revela a impossibilidade do sujeito de sustentar suas diferenças, constatando sua fragilidade no sistema de trocas sociais em que 
está inserido. A identidade é o resultado de um duplo processo: de identificação, por aproximação afetiva, e de diferenciação, decorrente do poder social de se impor como diferente do outro. Esse poder não é fortuito ou casual, mas está estritamente relacionado com o papel social desempenhado por esse sujeito nas suas trocas com os outros.

Em suas investigações, Sainsaulieu (1988) aponta, também, as estratégias de resistência dos trabalhadores às pressões organizacionais. Para o autor, embora existam ganhadores e perdedores nas trocas cotidianas, os que dominam não o fazem de forma absoluta, já "os dominados podem efetivamente encontrar meios de se opor brutalmente, de resistir continuamente, ou mesmo de suportar seu estado devido ao que aí ganham de recursos para combates exteriores" (Sainsaulieu, 1988, p. 334). Dessa forma, pode-se pensar que a dominação não é absoluta e os diferentes trabalhadores têm maiores ou menores possibilidades de resistência, dependendo dos processos de identificação desenvolvidos ao longo da história pessoal e profissional de cada um.

\section{TRAJETÓRIA METODOLÓGICA}

A pesquisa foi qualitativa e realizada com trabalhadores da Alfa, grupo empresarial catarinense reconhecido, nos meios acadêmicos e empresarias, pelo emprego de um modelo participativo de gestão (Coutinho, 2000). Foram investigados trabalhadores de três categorias profissionais diretamente ligadas às atividades produtivas (operadores, monitores e chefes de fábrica), de três fábricas ( $\mathrm{F}, \mathrm{C}$ e $\mathrm{A}$ ), localizadas no município de Joinville, em Santa Catarina.

A coleta de dados se realizou separadamente em cada uma dessas três unidades industriais. Os principais instrumentos utilizados foram a observação direta (com registro em diário de campo) e entrevistas semi-estruturadas com 43 trabalhadores. Na fábrica $\mathrm{F}$ foram realizadas 7 entrevistas (1 chefe, 2 monitores e 4 operadores), na unidade $\mathrm{C}$ foram entrevistados 15 trabalhadores ( 2 chefes, 5 monitores e 8 operadores), e na fábrica A foram feitas 21 entrevistas ( 2 chefes, 6 monitores e 13 operadores). Os dados principais foram complementados por meio de entrevistas com diretores, gerentes e outros profissionais da Alfa. As observações foram registradas em diário de campo de reuniões, consultas a documentos e informativos do grupo, e houve registro dos depoimentos dos trabalhadores.

Os dados principais - transcrição das entrevistas e registros do diário de campo - foram analisados utilizando um procedimento inspirado na análise de conteúdo proposta por Bardin (1994). Os resultados dessa análise foram contextualizados com os dados comple mentares. As entrevistas 
realizadas incluíam questões que buscavam detectar como se constituíram os processos de identificação profissional dos trabalhadores entrevistados, inclusive questões relativas a: trajetória profissional e formação, modelo ideal de trabalhador e envolvimento e participação na empresa. A análise dos dados coletados permitiu que se traçassem os perfis dos trabalhadores da Alfa.

\section{MODERNIZAÇÃO NA ALFA}

O grupo empresarial Alfa tinha suas plantas principais localizadas no município de Joinville, maior município do estado de Santa Catarina, situado em um importante pólo industrial no norte do estado. No período da coleta de dados, o grupo contava com um total aproximado de mil funcionários e era uma empresa de capital nacional, tendo sido posteriormente incorporada a uma multinacional.

Fundada na década de 1970, já a partir do início dos anos 1980 a Alfa passa a introduzir técnicas de gestão japonesa, com destaque aos Círculos de Controle de Qualidade (CCQs). Apesar de uma avaliação positiva desse programa pela administração da empresa, considerando que os trabalhadores apresentaram mais de 6 mil sugestões ao longo de 13 anos de funcionamento, uma série de razões levaram ao esgotamento dos CCQs. Esse esgotamento se deveu a críticas ao programa oriundas dos trabalhadores (inserção obrigatória nos grupos, reuniões fora do horário do expediente, sugestões não remuneradas) e também dos gestores (sugestões não produtivas para a empresa ou de caráter reivindicatório).

Em meados da década de 1990 foi implantado um novo programa participativo, o Programa Alfa de Administração Participativa (PAAP), considerado, pela administração, como mais amplo e dinâmico do que o anterior. Esse programa incluía desde um sistema de sugestões remuneradas até um programa de participação financeira. Além de mudar seu programa participativo, a empresa vinha passando por mudanças mais globais, abandonando uma política percebida como paternalista, buscando a profissionalização e a modernização, o que levou à renovação e à qualificação do seu quadro de funcionários.

A investigação revelou uma organização em crescimento, que fazia frente às pressões por competitividade por meio da utilização de diferentes ferramentas, com vistas à modernização. Entre essas ferramentas se destaca a introdução de novos equipamentos (robôs, painéis eletrônicos, embaladeiras automáticas, alimentação automática de matéria prima, informatização), de técnicas de gestão da produção (kanbans, células de produção) e de gestão de seus recursos humanos (gestão 
participativa, investimento em treinamento e formação, aumento das exigências de escolaridade) inspiradas no modelo japonês.

A observação das relações de trabalho em três fábricas diferentes do mesmo grupo mostrou que a busca por modernização não foi uniforme. O processo de trabalho tradicional, com linhas de montagem e fragmentação de tarefas, ainda tinha forte presença nas fábricas de $\mathrm{F}$ e $\mathrm{A}$ e mesmo na C. A primeira é a menor unidade do grupo, com poucos trabalhadores, processos de trabalho e equipamentos bastante simples e tradicionais. A fábrica A, matriz do grupo, passava por um momento de transição, buscando se modernizar, mas ainda utilizava equipamentos e processos produtivos antigos. A fábrica $\mathrm{C}$ era, entre as unidades pesquisadas, a que possuía processos e equipamentos mais modernos.

O grupo Alfa passava por um momento de transição, convivendo com o velho e o novo. Esse convívio apareceu de forma diferente em cada fábrica, mas mesmo a unidade mais moderna não pôde prescindir de trabalhadores experientes. Como decorrência dessa transição, a empresa não apresentava um modelo de gestão consolidado que pudesse ser uma referência para a identificação de seus funcionários. Nes se sentido, ela se distinguia de empresas como a hipermoderna (Pagès et al, 1987) ou como a estratégica (Enriquez, 1997). Embora apresentasse traços comuns com esses modelos, como o oferecimento de uma série de contrapartidas que favoreciam o engajamento e, conseqüentemente, o comprometimento de seus integrantes, a Alfa ainda não proporcionava garantias, como estabilidade e perspectiva de carreira, características de empresas com estratégias modernas de gestão.

A articulação entre pólos revelou o convívio, aparentemente harmonioso, entre o velho e o novo, propiciando o aumento da eficiência organizacional e, conseqüentemente, atendendo aos interesses de ampliação da lucratividade, o que se evidenciava pela superação das metas semestrais estabelecidas pelo programa de participação financeira.

Ainda que os gestores afirmassem a existência de um processo de transição sem rupturas entre as novas e velhas formas organizacionais, foi possível observar de diversas maneiras as contradições presentes na Alfa, quais sejam: presença de um discurso participativo, mas uma prática que permitia apenas uma distribuição bastante limitada do poder entre seus integrantes; ampla difusão de processos produtivos tradicionais (linhas de montagem) e equipamentos antigos, ao lado de práticas de gestão da produção, como just-in-time e kanban, e equipamentos modernos; uso de práticas tradicionais de gestão de recursos humanos, tais como salários na média do mercado e centralização de decisões, simultaneamente com práticas consideradas mais modernas, tais como gestão participativa e incentivo à formação; e a permanência de um grande número de trabalhadores antigos, apesar de a administração apresentar um discurso de ampla valorização do novo perfil de trabalhador. 
As contradições observadas na Alfa também têm sido verificadas em outros estudos na área de recursos humanos. Segundo Vasconcelos et al. (2004), a transição para novos modelos mais orgânicos de gestão de pessoas tem sido acompanhada por paradoxos e contradições entre o discurso e a prática, cuja percepção pelos integrantes das organizações produz efeitos não planejados. Em suas palavras,

\begin{abstract}
A piora do clima organizacional deve-se às frustrações geradas por estas contradições... Mais especificamente, quando "compram" os ideais de qualificação e aprendizagem pregados pelo discurso oficial, vários indivíduos sentem que este objetivo está em contradição com o trabalho mecânico que executam que os impedem de alcançar concretamente estes objetivos, construindo novas competências (VASCONCELOS et al., 2004, p.4).
\end{abstract}

As contradições que emergem no processo de transição da Alfa podem ser pensadas não apenas como dificuldade em romper com o velho e instalar novas práticas. Wolff (2003) questiona se os novos métodos de gestão efetivamente rompem com "a estrutura rígida, despótica e limitadora da atividade criativa, tal como se dava sob o trabalho taylorizado" (Wolff, 2003, 431). Em sua investigação sobre os PQTs, a autora concluiu que nessas novas políticas de gestão do trabalho ocorre uma expropriação não apenas dos gestos do trabalhador, tal como ocorria no taylorismo, mas também do próprio pensamento:

Longe do fim do trabalho taylorizado, portanto, o que verificamos é uma taylorização das capacidades cognitivas. Os operários são coagidos a apresentar idéias completamente desconexas e desprovidas de críticas que serão posteriormente organizadas pela administração, que as selecionará e utilizará em seu proveito, tal como a $\mathrm{OCT}^{3}$ faz em relação aos melhores tempos e ritmos dos operários. (WOLFF, 2003, p. 436).

\title{
PERFIS DOS TRABALHADORES
}

A transição da Alfa e a contradição entre o velho e o novo são reveladas de forma privilegiada pela análise dos perfis de seus integrantes. Apesar de ampla renovação do seu quadro funcional e de um discurso dos gestores que valorizava novos processos e trabalhadores, a empresa não apenas mantinha processos produtivos tradicionais, como também não podia prescindir de trabalhadores antigos e experientes.

A análise dos processos de identificação dos integrantes das três categorias profissionais investigadas revela a coexistência na Alfa de dois perfis de trabalhadores, antigos e novos, em particular quando se consideram as características dos níveis hierárquicos mais baixos: operadores e 
monitores de fábrica. Os antigos correspondiam àqueles que permaneceram, apesar das mudanças, seja porque a empresa não pôde prescindir do saber-fazer e da experiência adquirida por eles, ou porque ainda existia um grande número de postos de trabalho com tarefas bastante simples, repetitivas e desqualificadas. Contudo, os trabalhadores antigos não tinham nenhuma perspectiva de progresso profissional e corriam o risco de exclusão, como já havia acontecido com muitos colegas substituídos por jovens trabalhadores. Apesar de dedicados à Alfa, essa casa não lhes oferecia a mesma segurança de outrora.

O novo perfil de trabalhador, que estaria sendo gerado, apareceu com mais clareza na fábrica C, a mais moderna entre as três investigadas. Tratava-se de jovens com maior nível de instrução formal, iniciativa, habilidade para o desenvolvimento de tarefas variadas e expectativas de progresso profissional rápido. Vemos, aqui, a valorização de uma perspectiva individualista na qual é mais importante a carreira do que as relações sociais no grupo.

Também foi possível encontrar, na mesma fábrica, alguns jovens que valorizavam a participação e o espírito de grupo, um tema recorrente no discurso dos gestores da empresa. Com isso, temos a presença de valores opostos, tal como aponta Enriquez (1997): individualismo e grupismo. Contudo, a Alfa ainda não era capaz de promover a integração, o que aproximaria suas políticas de gestão do modelo de empresa estratégica. Dessa forma, a ampliação das repercussões negativas para a vida psíquica de seus integrantes pode ser estimulada, como mostram Enriquez (1997) e Lima (1996).

A busca por um novo perfil de trabalhador presente no discurso dos administradores da Alfa pode ser questionada. Embora reconhecesse a presença ainda forte do que um dos diretores chamou de colaborador braçal, a administração afirmava que vinha buscando um novo perfil, caracterizado como o colaborador da inteligência.

A transição rumo a um novo perfil, ainda segundo os gestores, estaria ocorrendo por meio de um processo de seleção natural, sem rupturas com o passado. De fato, a empresa vinha substituindo trabalhadores experientes por jovens com maior escolaridade. Essa substituição ocorria enquanto o número total de trabalhadores empregados se mantinha estável e a produtividade da Alfa crescia.

O tipo de trabalho desenvolvido em grande parte da empresa, organizado de forma tradicional, ainda tornava necessária a presença de um grande contingente de trabalhadores antigos. Mesmo os novos trabalhadores, com maior escolaridade, executavam, muitas vezes, tarefas simples e variadas, que não requeriam o uso da criatividade, qualidade que também vinha sendo pouco solicitada pelo modelo participativo implantado na Alfa. 
Os resultados dessa pesquisa não apontaram a presença de perfis profissionais homogêneos, o que poderia indicar a existência de modelos de identificação, fortemente consolidados, em cada categoria profissional. A realidade é complexa, e, como vimos, a contradição entre o velho e o novo está presente de forma diferente em cada tipo de trabalhador, em cada fábrica. Es sa heterogeneidade reitera a concepção de um sujeito ativo, capaz de resistir às pressões organizacionais, tal como afirma Sainsaulieu (1988).

\section{DIALÉTICA DA EXCLUSÃO/INCLUSÃO}

A emergência dos dois perfis profissionais observados na Alfa sugere que mesmo no interior das organizações produtivas é possível observar processos de exclusão social. Trabalhadores experientes, com um saber-fazer adquirido ao longo de sua trajetória profissional, são cada vez menos valorizados e temem serem jogados em um mercado marcado pelo desemprego e pelo trabalho precário.

O Brasil é um país historicamente excludente. Em estudo recente, Pochmann e Amorim (2003) traçam um amplo mapa da exclusão social brasileira, revelando o predomínio desse fenômeno nas regiões Norte e Nordeste. Principalmente nessas regiões, os autores encontraram o que chamaram de velha exclusão, caracterizada pela fome, famílias numerosas em situação de grave pobreza e analfabetismo. Os autores assinalam o aparecimento de uma nova forma de exclusão:

Em contrapartida, as regiões Sul e Sudeste, na maioria das vezes, abrigam municípios que, pelo Índice de Exclusão Social, não poderiam ser classificados como excluídos. No entanto, suas realidades sociais internas, principalmente nos mais populosos, são de grande desigualdade. Esse quadro parece ter se agravado a partir dos anos 1990 com a adoção de políticas econômicas de corte liberal. Identifica-se uma forma nova e peculiar de exclusão social nestes centros urbanos: ali um grande número de indivíduos, apesar de escolarizados, de terem experiência de assalariamento formal e possuírem famílias pouco numerosas, encontra-se em situação de desemprego e de insuficiência de renda. (POCHMANN e AMORIM, p. 73, 2003).

No estudo acima citado, os autores fazem um mapeamento de todas as cidades brasileiras, a partir de sete indicadores que compõem o índice de exclusão social estabelecido por eles. Os indicadores utilizados são: pobreza, emprego formal e desigualdade, que compõem o índice padrão digno de vida; anos de estudo (escolaridade) e alfabetização compõem o índice de conhecimento; concentração de jovens e violência compõem o índice de risco juvenil. 
O índice de exclusão social pode variar de zero a 1, e quanto mais próximo a zero estiver o indicador, pior é a avaliação das condições de vida de uma determinada localidade. O estado de Santa Catarina destaca-se pela predominância de indicadores positivos, sendo uma das unidades da Federação com menor número de municípios com indicadores de extrema exclusão social (índice menor do que $0,4)$.

A cidade de Joinville, onde se localiza o grupo Alfa, é um dos 15 municípios catarinenses entre os 100 brasileiros com menor grau de exclusão social, ocupando a $64^{\mathrm{a}}$ posição na lista elaborada por Pochmann e Amorim (2003). O índice total calculado para essa cidade, considerando todos os indicadores analisados, foi de 0,643. Entretanto, analisando cada indicador separadamente, verifica-se que alguns estão bem próximos de 1,0, enquanto outros estão bem abaixo. Os dois indicadores mais baixos da cidade compõem o índice padrão digno de vida, e são: emprego formal, com índice de 0,295, refere-se à proporção desses trabalhadores em relação à população em idade ativa; e desigualdade, com índice de 0,266, o qual é "calculado pela razão entre a quantidade de chefes de família que ganham acima de dez salários mínimos sobre o número de chefes de família que ganham abaixo disso" (Pochmann e Amorim, 2003, p. 16).

Os indicadores acima estão profundamente associados à situação precária de trabalho, na medida em que apontam baixos índices de trabalho formal e de nível de renda dos cidadãos. Dessa forma, é possível observar que Joinville, conhecida como um rico pólo industrial catarinense, padeceria, segundo Pochmann e Amorim(2003), de uma nova forma de exclusão social.

A nova forma de exclusão que a cidade apresenta pode ser pensada como o resultado de processos desenvolvidos no cotidiano das relações de trabalho. Esse aspecto foi observado na Alfa, onde a inclusão dos novos ocorre paralelamente à exclusão dos antigos, construindo uma realidade contraditória, na qual a presença de uns nega a de outros.

Considerando dialética como "o modo de compreendermos a realidade como essencialmente contraditória e em permanente contradição" (Konder, 2000, p. 8), é possível pensar que estaria se construindo no interior de uma organização industrial o que Sawaia (1999) denomina a dialética da exclusão/inclusão:

A exclusão é processo complexo e multifacetado, uma configuração de dimensões materiais políticas, relacionais e subjetivas. É processo sutil e dialético, pois só existe em relação à inclusão, como parte constitutiva dela. Não é uma coisa ou um estado, é processo que envolve o homem por inteiro e suas relações com os outros. Não tem uma única forma e não é uma falha do sistema, devendo ser combatida como algo que perturba a ordem social, ao contrário ele é produto do funcionamento do sistema. (SAWAIA, 1999, p. 9). 
Os trabalhadores antigos e novos atuavam na Alfa de forma complementar, sendo necessário o trabalho de todos para o bom funcionamento da empresa. Apesar disso, havia um discurso de valorização apenas dos novos, denominados pela administração colaboradores da inteligência; já os antigos ou colaboradores braçais, deveriam ser eliminados por meio de um processo de exclusão, contraditoriamente considerado como uma forma de seleção natural, da qual sobrevivem apenas os mais aptos. Essa valorização de uns e desvalorização de outros configura a dialética da exclusão/inclusão que se estabeleceu na Alfa.

No discurso dos trabalhadores antigos estava presente o medo de também serem excluídos, tal como já acontecera com outros colegas. Percebiam que seu tempo estaria prestes a se esgotar, que não tinham perspectiva de carreira na empresa. A idade e a escolaridade constituem dois elementos valorizados no mercado de trabalho, que dificultam ainda mais a inclusão dos antigos, como aparece claramente na fala de uma operadora antiga:

É... sei lá, às vezes eu penso [...] em estudar, quem sabe arrumar uma coisa melhor, depois eu penso: já tenho 40 anos, logo posso me aposentar, não adianta ficar lutando muito, eu acho assim que as pessoas novas, sim, [...] as minha filhas eu incentivo bastante, agora eu, não sei, às vezes eu penso assim, eu quero fazer o $2^{\circ}$ grau, .[...] sei lá, de repente pode surgir uma vaga no mural, eu posso fazer um teste, passar, melhorar, mas por outro lado eu penso assim: "pô tem tanta moça bonita, porque que eles vão querer eu lá?" (operadora de máquinas, 40 anos, $2^{\circ}$ grau incompleto).

O medo do desemprego e da exclusão coloca os trabalhadores em uma situação de maior vulnerabilidade social (Segnini, 2001; Kovács, 2003).

\footnotetext{
A exclusão do emprego e da empresa implica isolamento, significa não ter identidade social e não ter palavra para defender seus interesses. A instabilidade econômica, familiar, emocional e profissional leva à perda de esperança e incapacidade de aproveitar uma nova oportunidade. Ao mesmo tempo, a generalização do emprego precário e a falta de perspectivas para um avanço profissional produzem um ambiente de angústia e insegurança. (KOVÁCS, 2003, p. 39).
}

A fala da operadora antiga mostra o quanto a desvalorização externa pode ser interiorizada pelo sujeito, que acaba se percebendo como impossibilitado a aspirar um futuro melhor. Já um jovem trabalhador, com maior escolaridade e desempenhando atividades mais complexas e valorizadas, pode perceber-se como capaz de enfrentar mesmo uma eventual crise da empresa. Essa perspectiva mais positiva é revelada na fala apresentada a seguir. Mesmo diante de um problema concreto, o crescimento dos 
índices de desemprego no Basil, este jovem operador se sente em condições de enfrentar eventuais dificuldades futuras:

[...] se a Alfa diminui vendas no mercado, a única coisa que o funcionário vai se preocupar é se ele vai ficar desempregado ou não... Eu não tenho medo de ficar desempregado... eu sou alguém que sempre procura participar, eu acho que uma pessoa que sempre procura participar hoje no mercado sempre tem um lugar, sempre vai ter um lugar (operador de processo, 25 anos, $2^{\circ}$ grau completo, cursando técnico).

As falas dos dois operadores são exemplos de como o crescimento da desigualdade social no Brasil, um fenômeno social, repercute diferentemente na constituição da identidade de cada sujeito. As categorias para a análise dos processos que permitem diferentes sujeitos identificarem-se como incluídos ou excluídos nas novas configurações do mundo do trabalho são múltiplas; além das categorias citadas, idade e escolaridade, os exemplos dados também apontam para a categoria gênero, sendo justamente a trabalhadora quem se percebe como menos portadora de perspectivas positivas no futuro.

\section{CONSIDERAÇÕES FINAIS}

O atual contexto de reestruturação produtiva vem pressionando as organizações para modernizarem-se, com vistas a fazerem frente às exigências de competitividade. Assiste-se à transição para novos modelos, mais flexíveis, de gestão. As empresas flexíveis tendem a focalizar suas atividades em um núcleo central, o que implica a

existência de um número reduzido de empregos de base bem pagos, estáveis e com perspectiva de desenvolvimento profissional. Para este segmento de trabalhadores a empresa constitui um lugar de cidadania, de sociabilidade, de expressão e de subjetividade. No entanto, a externalização das restantes atividades leva a difusão de formas de empregos periféricos na sua maioria precários [...] Essa evolução pode favorecer os mais qualificados e autônomos, mas dificilmente os menos qualificados e autônomos e de modo nenhum aqueles que se encontram em uma situação de exclusão. (KOVÁCS, 2003, p. 38-9).

Neste artigo, foi analisado o processo de transição da Alfa rumo à modernização. Como se mostrou a transição por que passava a empresa não permitiu a estruturação de um modelo consolidado de gestão que favorecesse a identificação de seus integrantes. Observaram-se as contradições entre velhas e novas formas de gestão presentes na organização. Essas contradições foram evidenciadas, particularmente, por meio dos dois perfis de trabalhadores da empresa: antigos e novos. O discurso de ambos revela a 
situação de exclusão dos primeiros, enquanto para o jovem trabalhador a empresa parece constituir um lugar de expressão de subjetividade e de poder, permitindo que ele se sinta capaz de enfrentar até mesmo o desemprego.

Foi possível identificar a presença da dialética da exclusão/inclusão na Alfa. Apesar da transição apontada, é importante considerar que a consolidação de um modelo mais flexível de gestão não rompe, mas ao contrário tende a potencializar, os processos de exclusão (Kovács, 2003). Os fenômenos observados no interior das organizações fazem parte do contexto mais amplo das relações de trabalho o Brasil. O olhar para o cotidiano dessas relações permite revelar as tramas e os dramas por trás dos indicadores de desemprego e exclusão.

A partir da consciência sobre as novas e velhas formas de exclusão, é importante pensar em alternativas coletivas que rompam com elas. Deve-se evitar a culpabilização individual dos excluídos, não apenas por meio de políticas públicas inclusivas, mas propiciando aos sujeitos, individuais e coletivos, possibilidades alternativas de identificação.

Ao apresentar os resultados de uma investigação realizada em um grupo industrial em transição rumo a um modelo de gestão mais flexível, buscoutse evidenciar as contradições e paradoxos das estratégias de gestão que vinham sendo implementadas ali. Esses resultados corroboraram a hipótese de que a dialética da exclusão/inclusão já está presente no interior das organizações produtivas. Tal hipótese só poderá ser consolidada com a continuidade de estudos organizacionais com o mesmo enfoque. Sendo assim, considera-se relevante o desenvolvimento de novas investigações sobre os processos de identificação em outras organizações, tanto aquelas com estratégias de gestão ainda não consolidadas como as consideradas flexíveis, com o objetivo de desvelar a dialética da exclusão/inclusão.

\section{NOTAS}

1 Além da abordagem afetiva/atitudinal, Bastos (1996) descreve as seguintes abordagens: “... instrumental/side-bets, que vê o comprometimento como produto das recompensas e custos associados à permanência na organização; normativa, na qual o comprometimento é visto como o conjunto de pressões normativas internalizadas para que o indivíduo se comporte congruentemente com os objetivos e metas da organização; comportamental, na qual o comprometimento existe em relação a comportamentos ou atos com cognições que fortalecem tais vínculos, tais como sentimentos de autoresponsabilidade; e sociológica, para a qual o vínculo é conceituado em termos das relações de autoridade que governam o controle do empregador e a subordinação do empregado” (p. 108/109). 
${ }^{2}$ Lima (1996) está se referindo às empresas estratégicas, expressão criada por Enriquez (1997) que será apresentada a seguir.

${ }^{3}$ OCT: organização científica do trabalho, expressão cunhada por Taylor para referir sua proposta de organização do processo produtivo.

\section{REFERÊNCIAS BIBLIOGRÁFICAS}

ANTUNES, R. Os sentidos do trabalho: ensaio sobre a afirmação e a negação do trabalho. São Paulo: Boitempo, 2000.

BARDIN, L. Análise de conteúdo. Lisboa: Edições 70, 1994.

BASTOS, A. V. B. Comprometimento no trabalho: os caminhos da pesquisa e seus desafios teóricometodológicos. In: TAMAYO, Á. et al. Trabalho, organizações e cultura. São Paulo: Cooperativa de Autores Associados, 1996. p. 105-127.

CIAMPA, A. C. Identidade humana como metamorfose: a questão da família e do trabalho e a crise de sentido do mundo moderno. Interações: Estudo e Pesquisa em Psicologia, São Paulo, v. 3, n. 6, p. 87101, 1998.

CLÔT, Y. Le travail dans l'automobile: du cognitif au subjetif. L'Orientation Scolaire et Professionnelle, Paris, v. 19, n. 4, p. 311-319, 1990.

CORIAT, B. Pensar pelo avesso: o modelo japonês de gestão. Rio de Janeiro: Ed. da UFRJ, 1994.

COUTINHO, M. C. Trabalho e construção da identidade. Psicologia em Estudo, v. 4, n. 1, p. 29-43, 1999.

COUTINHO, M. C. Entre o velho e o novo: estratégias de participação no trabalho. 2000. 284 p. Tese (Doutorado em Ciências Sociais) - Universidade Estadual de Campinas, Campinas.

ENRIQUEZ, E. O indivíduo preso na armadilha da estrutura estratégica. Revista de Administração de Empresas, São Paulo, v. 37, n. 1, p. 18-29, 1997.

GUARESCHI et al. Pobreza, violência e trabalho: a produção de sentidos de meninos e meninas de uma favela. Estudos de Psicologia, v. 8, n. 1, p. 45-53, 2003.

JACQUES, M. G. C. Identidade e trabalho: uma articulação indispensável. In: TAMAYO, A. et al. Trabalho, organizações e cultura. São Paulo: Cooperativa de Autores Associados, 1996. p. 41-47. 
KONDER, L. O que é dialética. São Paulo: Brasiliense, 2000. Coleção Primeiros Passos.

KOVÁCS, I. Reestruturação empresarial e do emprego. In: PICCININI, V. C. (Eds.). Caderno de debates: transformações do trabalho no contexto da reestruturação econômica. Porto Alegre: Gráfica da UFRGS, 2003. p. 31-44.

LABOUNOUX, G. Socialité organisationnelle. In: JUAN, S (Eds.). Organisation et management en question(s). Paris: L'Harmattan, 1987. p. 64-79.

LIMA, M. A. Os equívocos da excelência: novas formas de sedução na empresa. Petrópolis: Vozes, 1996.

PAGÈS, M. et al. O poder das organizações: a dominação das multinacionais sobre os indivíduos. São Paulo: Atlas, 1987.

PATEMAN, C. Participação e teoria democrática. Rio de Janeiro: Paz e Terra, 1992.

POCHMANN, M.; AMORIM, R. (Eds.). Atlas da exclusão social no Brasil. São Paulo: Cortez, 2003.

RUAS, R. et al. Avanços e impasses do modelo japonês no Brasil. In: HIRATA, H. S. (Eds.). Sobre o modelo japonês. São Paulo: Edusp, 1993, p. 103-122.

SAINSAUliEU, R. L'Identité au Travail. Paris: Presses de la Fondation Nationale des Sciences Politiques, 1988.

SALERNO, M. Modelo japonês, trabalho brasileiro. In: HIRATA, H. S. (Eds.). Sobre o modelo japonês. São Paulo: Edusp, 1993. p.139-152.

SAWAIA, B. Introdução: exclusão ou inclusão perversa? In: SAWAIA, B. (Eds.). As artimanhas da exclusão: análise psicossocial e ética da desigualdade social. Petrópolis: Vozes, 1999, p. 7-13.

SEGNINI, L. R. P. Entre o desemprego e a engrenagem do emprego precário. In: IV ENCONTRO REGIONAL DE ESTUdOS DO TRABALHO DA ABET, 2001, Porto Alegre. Anais. Porto Alegre: Softwaresi, 2001.

VASCONCELOS, I. et al. Paradoxos organizacionais, gestão de pessoas e tecnologia na Souza Cruz. RAE-eletrônica, São Paulo, v. 3, n. 2, art. 25, 2004. Disponível em <http://www.rae.com.br/eletrônica $>$. Acessado em 21 jan. 2005.

WOLFF, S. Qualidade total e informática: a constituição do novo homem máquina. Idéias. Dossiê: O Avesso do Trabalho, v. 10, n. 1, p. 413- 454, 2003. 


\section{Artigo recebido em 30.04.2004. Aprovado em 14.09.2005.}

\section{Maria Chalfin Coutinho}

Professora do Departamento e do Programa de Pós-Graduação em Psicologia da UFSC. Doutora em Ciências Sociais pela Unicamp.

Interesses de pesquisa nas áreas de trabalho e constituição do sujeito.

E-mail: chalfin@mbox1.ufsc.br

Endereço: Rua Dep. Antônio Edu Vieira, 1304, ap. 202 A, Florianópolis - SC, 88040-001. 